\title{
Evaluation of Enterprise Cooperation through Information Exchange
}

\author{
Marcius Fabius Carvalho ${ }^{1,2}$ and Ralph Santos Silva ${ }^{1}$ \\ ${ }^{1}$ Centro de Tecnologia da Informação Renato Archer - CTI, \\ Rodovia Dom Pedro I, Km 143,5 \\ 13069-901 - Campinas, SP, Brazil \\ ${ }^{2}$ Assistant Professor Civil Engineering Faculty - State University of Campinas \\ Campinas, Brazil \\ marcius.carvalho@cti.gov.br
}

\begin{abstract}
Considering that cooperation among enterprises contributes significantly to improve the product performance in a supply chain, this work presents a method for evaluating the enterprise cooperation focused on the exchange of information among firms. Two indexes are used: the intensity, which seeks to measure the amount of information shared; and the extension, which seeks to measure how many stages of the supply chain are exchanging information both upstream and downstream. The proposed method was applied to eighteen auto part firms of Campinas region in Brazil. The intensity and the extension indexes for each enterprise were measured and some relevant conclusions regarding to information exchange for automotive sector are presented.
\end{abstract}

Keywords: Supply Chain, Enterprise Cooperation, Information Exchange, automotive industry.

\section{Introduction}

It is recognized that supply chain management requires the inter- and intraorganizational integration relationships and coordination of different types of flows as material, founds and information. Information technology to improve supply chain performance as point of sale scanner and electronic data interchange are available, nonetheless the performance of the supply chain has never been worse [1].

The true supply chain excellence will only come from making a digital business transformation and when done effectively, it enables companies to share information that can dramatically shorten processing time, eliminate value-depleting activities, and improve quality, all of which are fundamental to long-term success [2]. The importance of strategic collaboration and definition of supply chain integration as the degree to which a manufacturer collaborates with its supply chain partners and collaboratively manages intra- and inter-organization processes was highlighted by [3].

Despite of the importance of information flow, little attention has been given in the literature to measure the magnitude and the effectiveness of information exchange for the coordination of enterprises with their supply chain. This is a paradox since the 
integration and coordination, through information technology can be largely utilized in an accessible cost.

In one of the few papers in the literature addressing the issue of information exchange among enterprises examine the relationship between the information availability and successful implementation of integrated logistics systems inside of an individual company [4]. Scales for measuring supply chain integration and five different strategies were identified was developed by [5]. Each of these strategies is characterized by a different "arc of integration", representing the direction (towards suppliers and/or customers) and degree of integration activity. There was consistent evidence that the widest degree of arc of integration with both suppliers and customer shad the strongest association with enterprise performance improvement. A Research [6] extended the work of [4] by providing a general tool that can be used for both the macro and micro levels to evaluate the relative performance of a given information flow structure. The measure, a single 2-tuple index, was derived from information about a firm's relationship with suppliers and customers. The measure encompasses both the depths of information exchanges, that is how far up or down in the supply chain a firm exchanges information as well as the intensity of the information that is exchanged and used in logistics planning. Intensity is measured by gauging the degree to which demand, inventory, and production planning is shared and used by the firms in both directions of the supply chain.

This study takes the work [6] to answer the question: What is the actual level of integration of auto parts industry sited in Campinas region? The next section presents the method to evaluate the information exchange. In the following the methodology defines the sample specification and questionnaire composition. In the section four the results are analyzed and finally in the section five the conclusion and limitation of the research are presented.

\section{Supply Chain Coupling Index}

The method for describing the degree to which a firm is "coupled" within its supply chain, called Supply Chain Coupling Index SCCI based on two indicators [6]: Information Extent (IE) and Information Intensity (II). IE describes how deep into the network (in either direction of customers or suppliers) the information is exchanged, whereas II describes the richness, and amount of the information used (either in the direction of customers or suppliers). Then SCCI is defined as:

$$
\mathrm{SCCI}=\mathrm{EI}+\mathrm{II}
$$

The enterprise will be less coupled within its supply chain as the value of both indexes (IE and II) approaches zero. On the other hand, the enterprise becomes more coupled as SCCI approaches unity. The ideal situation, EI = II = 1, means all relevant information from all members of the supply chain (customers, suppliers) are shared.

\subsection{Information Extent (IE)}

The EI index describes how deep the information can be seen and used into the network (in either direction of customers and suppliers). It is defined as the weighted 
average of two indexes: the IE toward customers $\left(\mathrm{IE}^{\mathrm{d}}\right)$ and the IE toward suppliers $\left(\mathrm{IE}^{\mathrm{u}}\right)$. Thus, the degree of IE is defined as:

$$
\mathrm{IE}=\mathrm{k}_{1} \cdot \mathrm{IE}^{\mathrm{c}}+\mathrm{k}_{2} \cdot \mathrm{IE}^{\mathrm{s}}
$$

Where IEc is the information extent toward customers, IEs is the information extent toward suppliers, $\mathrm{k} 1$ and $\mathrm{k} 2$ are weights toward customer and suppliers respectively. $\mathrm{k} 1, \mathrm{k} 2$ are between 0 and 1 and sum one.

\subsection{Information Intensity (II)}

The II index describes the richness, and amount of the information used (either in the customer and supplier direction)and, similarly, is composed of two indexes Eq.3.

$$
\mathrm{II}=\mathrm{l}_{1} \cdot \mathrm{II}^{\mathrm{c}}+\mathrm{l}_{2} \cdot \mathrm{II}^{\mathrm{s}}
$$

The IIc and IIs indicate the intensity of information exchange of the firm with its customer and supplier respectively and 11,12 are weights that sum equal 1 . To be coordinated in an effective way a supply chain must consider at minimum the exchange of information of: demand (D), inventory (I), capacity (C), and production scheduling $(\mathrm{P})$. Assuming Dc for demand information from the customer and so on, the information intensity index related to the customer can be written as:

$$
\mathrm{II}^{\mathrm{c}}=\mathrm{w}_{1}{ }^{\mathrm{c}} \mathrm{D}^{\mathrm{c}}+\mathrm{w}_{2}{ }^{\mathrm{c}} \mathrm{I}^{\mathrm{c}}+\mathrm{w}_{3}{ }^{\mathrm{c}} \mathrm{C}^{\mathrm{c}}+\mathrm{w}_{4}{ }^{\mathrm{c}} \mathrm{P}^{\mathrm{c}}
$$

Where w1c, w2c, w3c and w4c are weights that sum equal one.

And, also assuming Ds for demand information toward suppliers and so on, the customer information intensity index related to customer can be written as:

$$
\mathrm{II}^{\mathrm{s}}=\mathrm{w}_{1}{ }^{\mathrm{s}} \mathrm{D}^{\mathrm{s}}+\mathrm{w}_{2}{ }^{\mathrm{s}} \mathrm{I}^{\mathrm{s}}+\mathrm{w}_{3}{ }^{\mathrm{s}} \mathrm{C}^{\mathrm{s}}+\mathrm{w}_{4}{ }^{\mathrm{s}} \mathrm{P}^{\mathrm{s}}
$$

\section{Methodology}

The supply chain coupling evaluation was composed of three main activities: sample definition, questionnaire composition, application and analysis of results.

\subsection{Sample Definition}

Taking the theoretical referential it was structured and conducted a field research involving medium and large size auto parts enterprises of Campinas region, Brazil with the objective to answer the question: What is the actual level of integration of auto parts industry sited in Campinas region? This area has been chosen due to a significant number of auto parts firms in the region to be an area on vanguard in the utilization of advanced technology and methodology mainly associated to information exchange. The automotive sector has been chosen since it is one of those dependents of information exchange for the success of its supply chain. Also the automotive sector in Brazil has contributed with $18 \%$ of the Gross Domestic Product (GDP). Eighteen enterprises, representing suppliers of first and second level of final assembly plant were participating in the research and fifteen questionnaires were considered valid. Medium and large enterprises were chosen since they are those with perspective of 
best information technology utilization with their partners. Particularly, assembly plants were neglected since they are not accessible as auto part enterprises are.

\subsection{Questionnaire Composition}

The questionnaire was structured in four parts. The two initial parts was focused on qualitative and quantitative measures to identify the size, the position of the participant enterprise in the supply chain, its main suppliers and customers, and internal importance attributed to the information technology. The two last parts were dedicated to determine the Supply Chain Coupling - SCCI as a result of upstream and downstream information coupling. Due to lack of space, this work presents part1 and analyze only the results of the part 3 and part 4 of the questionnaire.

Part 1

Distribution of enterprises according to number of employees

\begin{tabular}{|c|r|r|r|r|}
\hline Workers & +1500 & $751 \rightarrow 1500$ & $251 \rightarrow 750$ & $0 \rightarrow 250$ \\
\hline Enterprise & E2, E4, E9 & E5, E10 & $\begin{array}{l}\text { E6, E8, E11, E15, } \\
\text { E16, E17, E18 }\end{array}$ & E3,E12, E14 \\
\hline
\end{tabular}

Part 3

Four questions directed to the supplier, to the supplier of the direct supplier, to the direct customer and to the customer of the customer were defined to identify the Information extent Index (IE) as shown in Table 1.

Part 4

This part of the questionnaire was designed for identifying the intensity of firm information exchange from and to both customers and suppliers and type of information used. In general are Demand (D), Production planning (P), Capacity(C) and Storage (S), as shown in Table 2.

\section{Discussion of Results}

The Information Extent (IE) for the fifteen enterprises is presented in the Table 1 through as binary form. " 1 " means information exchange while " 0 " means no significant information exchange between coupled enterprises. This work considers enterprises sited until two levels upstream to the reference enterprise and two levels downstream to the reference enterprise. Also, weights factors were associated to each level $(\mathrm{K}=0,35$ to the first level and $\mathrm{K}=0,15$ for the second level), to express the relative importance of the information. The columns 3 and 4 present the respondent perception related with the cooperation by information exchange with the first level partners up and downstream of the reference enterprise. The second level $\mathrm{IE}^{\mathrm{ss}}$ index is less relevant than the first level $\mathrm{IE}^{\mathrm{s}}$ index then its weight is lower.

According to the respondent the information exchange is more intensive with first and second order customers than with the suppliers. It can be confirmed by the dendogram generated from Table 1 and presented in Fig. 1. It also shows the group of enterprises with same behavior regarding to information exchange. The Enterprise 5 
(E5), it is totally uncoupled from its upstream neighbor, that is a steel partner, large and strong enough to negotiate with its clients. Table 2 shows the Information Intensity index (II) regarding to the Demand, Storage, Capacity and Production Planning data. Also, the binary representation was assumed (1 information exchange; 0 no information exchange) and the same weight was attributed to the upstream and downstream information exchange, although any other value should be used to consider different way to exchange information. The results demonstrate that actual information exchange practice of the enterprises is inferior to the perception of the respondent expressed in Table 1.

Table 1. Information Extent

\begin{tabular}{|c|c|c|c|c|c|}
\hline Enterprise & $\begin{array}{c}\text { Supplier of } \\
\text { supplier } \\
\mathrm{K}^{\mathrm{ss}}=0,15\end{array}$ & $\begin{array}{c}\text { Immediate } \\
\text { supplier } \\
\mathrm{K}^{\mathrm{s}}=0,35 \\
\end{array}$ & $\begin{array}{c}\text { Immediate } \\
\text { Customer } \\
\mathrm{K}^{\mathrm{c}}=0,35 \\
\end{array}$ & $\begin{array}{l}\text { Customer of } \\
\text { Customer } \\
\mathrm{K}^{\mathrm{cc}}=0,15\end{array}$ & $\begin{array}{l}\text { Index } \\
\text { IE }\end{array}$ \\
\hline E2 & 1 & 1 & 1 & 1 & 1,0 \\
\hline E3 & 0 & 1 & 1 & 0 & 0,7 \\
\hline E4 & 1 & 1 & 1 & 1 & 1,0 \\
\hline E5 & 0 & 0 & 1 & 0 & 0,35 \\
\hline E6 & 0 & 1 & 1 & 0 & 0,7 \\
\hline E8 & 1 & 1 & 1 & 1 & 1,0 \\
\hline E9 & 0 & 1 & 1 & 0 & 0,7 \\
\hline E10 & 0 & 1 & 1 & 0 & 0,7 \\
\hline E11 & 0 & 1 & 1 & 0 & 0,7 \\
\hline E12 & 0 & 1 & 1 & 0 & 0,7 \\
\hline E14 & 1 & 1 & 1 & 1 & 1,0 \\
\hline E15 & 0 & 1 & 1 & 1 & 0,85 \\
\hline E16 & 1 & 1 & 1 & 1 & 1,0 \\
\hline E17 & 0 & 0 & 1 & 1 & 0,5 \\
\hline E18 & 0 & 0 & 1 & 1 & 0,5 \\
\hline Mean & $5 / 15=0,33$ & $12 / 15=0,8$ & $15 / 15=1$ & $8 / 15=0,53$ & $11,4 / 15=0,8$ \\
\hline
\end{tabular}

Although the respondent recognizes the importance of information exchange as an element for enterprise competitiveness, the individual measures indicate low level of information exchange than they believe. Second, is observed more information exchange with suppliers than with clients. Most of these enterprises are first level supplier of car manufacturers.

To confirm this unexpected result an unstructured interview with some enterprises was developed. They say to appeal to secondary data to plan its production. Example, new car sale variation can indicate tendencies in future car maker orders. This tendency influences the enterprise production planning and must be considered although not pointed out by the car makers. This finding shows the importance of second level information and the low cooperation among enterprises participants of the research. A resume of Supply Chain Coupling Index is presented in Table 3. The E16 presents the best coupling index and E05 one enterprise with the worst coupling index. These 


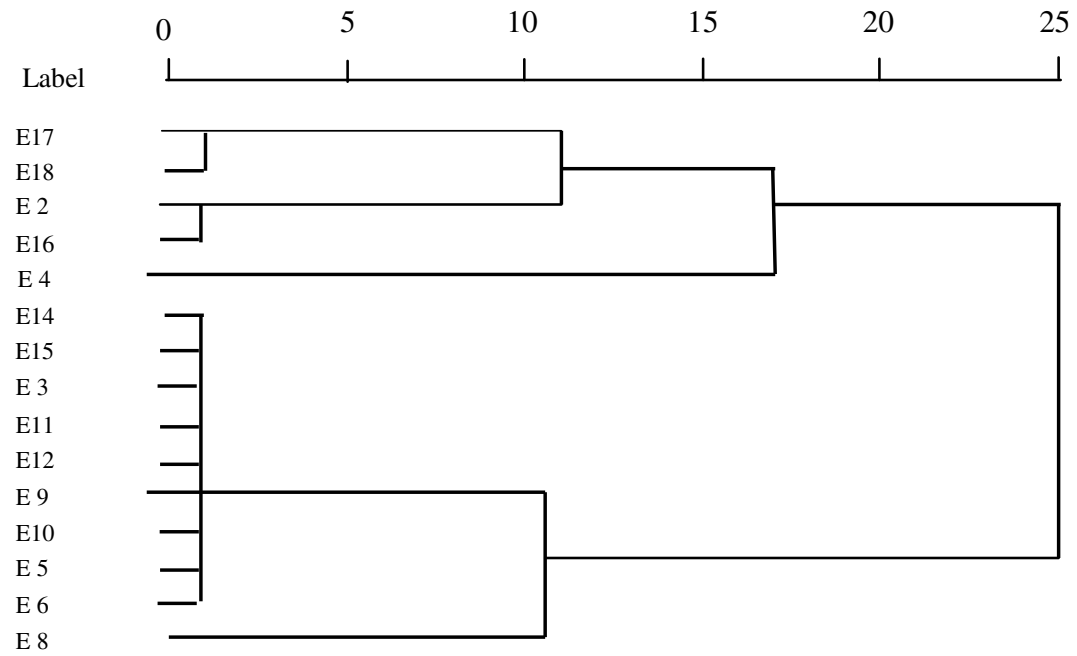

Fig. 1. Customer information exchange dendogram

Table 2. Information Intensity

\begin{tabular}{|c|c|c|c|c|c|c|c|c|c|c|c|}
\hline \multirow[t]{2}{*}{ Enterprise } & \multicolumn{4}{|c|}{$\begin{array}{l}\text { Neighbor } \\
\text { Supplier }\end{array}$} & \multirow[t]{2}{*}{$\begin{array}{c}\text { Index } \\
\text { II }^{\mathrm{f}}\end{array}$} & \multicolumn{4}{|c|}{ Neighbor Client } & \multirow[t]{2}{*}{$\begin{array}{c}\text { Index } \\
\text { II }^{\mathrm{c}}\end{array}$} & \multirow[t]{2}{*}{$\begin{array}{c}\text { Index II } \\
\left(0,5^{*} \mathrm{II}^{\mathrm{f}}+0,5^{*} \mathrm{II}^{\mathrm{c}}\right)\end{array}$} \\
\hline & $\mathrm{D}$ & I & $\mathrm{C}$ & $\mathrm{P}$ & & D & I & C & $\mathrm{P}$ & & \\
\hline E2 & 1 & 0 & 0 & 0 & 0,25 & 1 & 1 & 1 & 1 & 1 & 0,625 \\
\hline E3 & 1 & 1 & 1 & 1 & 1 & 1 & 0 & 0 & 0 & 0,25 & 0,625 \\
\hline E4 & 1 & 1 & 1 & 1 & 1 & 1 & 1 & 1 & 0 & 0,75 & 0,875 \\
\hline E5 & 0 & 0 & 0 & 1 & 0,25 & 1 & 0 & 0 & 0 & 0,25 & 0,25 \\
\hline E6 & 1 & 0 & 0 & 0 & 0,25 & 1 & 0 & 0 & 0 & 0,25 & 0,25 \\
\hline E8 & 1 & 1 & 1 & 1 & 1 & 1 & 0 & 1 & 0 & 0,50 & 0,75 \\
\hline E9 & 1 & 0 & 0 & 0 & 0,25 & 1 & 0 & 0 & 0 & 0,25 & 0,25 \\
\hline E10 & 1 & 0 & 0 & 1 & 0,50 & 1 & 0 & 0 & 0 & 0,25 & 0,375 \\
\hline E11 & 1 & 1 & 1 & 0 & 0,75 & 1 & 0 & 0 & 0 & 0,25 & 0,50 \\
\hline E12 & 1 & 0 & 0 & 0 & 0,25 & 1 & 0 & 0 & 0 & 0,25 & 0,25 \\
\hline E14 & 1 & 0 & 0 & 0 & 0,25 & 1 & 0 & 0 & 0 & 0,25 & 0,25 \\
\hline E15 & 1 & 0 & 0 & 0 & 0,25 & 1 & 0 & 0 & 0 & 0,25 & 0,25 \\
\hline E16 & 1 & 1 & 1 & 1 & 1 & 1 & 1 & 1 & 1 & 1 & 1 \\
\hline E17 & 1 & 0 & & & 0,75 & & 0 & & 1 & 0,75 & 0,75 \\
\hline E18 & 1 & 0 & & & 0,50 & & 0 & & 1 & 0,75 & 0,625 \\
\hline Mean & & & & & $\begin{array}{c}0,82 / 15 \\
=0,55\end{array}$ & & & & & $\begin{array}{c}7 / 15=0 \\
47\end{array}$ & $7,62 / 15=0,51$ \\
\hline
\end{tabular}


Table 3. Supply Chain Coupling Index - SCCI

\begin{tabular}{|c|c|c|c|}
\hline Enterprise & $\begin{array}{c}\text { Index } \\
\text { EI }\end{array}$ & $\begin{array}{c}\text { Index } \\
\text { II }\end{array}$ & $\begin{array}{c}\text { SCCI } \\
0,5 * \text { EI+0,5*II }\end{array}$ \\
\hline E2 & 1 & 0,625 & 0,8125 \\
\hline E3 & 0,7 & 0,625 & 0,6625 \\
\hline E4 & 1 & 0,875 & 0,9375 \\
\hline E5 & 0,35 & 0,25 & 0,3 \\
\hline E6 & 0,7 & 0,25 & 0,475 \\
\hline E8 & 1 & 0,75 & 0,875 \\
\hline E9 & 0,7 & 0,25 & 0,475 \\
\hline E10 & 0,7 & 0,375 & 0,5375 \\
\hline E11 & 0,7 & 0,50 & 0,6 \\
\hline E12 & 0,7 & 0,25 & 0,475 \\
\hline E14 & 1 & 0,25 & 0,625 \\
\hline E15 & 0,85 & 0,25 & 0,55 \\
\hline E16 & 1 & 1 & 1 \\
\hline E17 & 0,5 & 0,75 & 0,625 \\
\hline E18 & 0,5 & 0,625 & 0,5625 \\
\hline MEAN & $11,4 / 15=0,8$ & $7,62 / 15=0,51$ & 0,6342 \\
\hline
\end{tabular}

indexes represent the point of view of the respondent about cooperation of its enterprise with the supply chain. Also it allows to compare one enterprise against its partners or competitors.

\section{Conclusion and Limitation}

An analysis of cooperation through information exchange of the Campinas auto parts sector was proposed based in a sample of 15 questionnaires applied to in medium and large size enterprises directly coupled to the car makers or enterprises coupled to the first level suppliers.

The main conclusions are:

1) All the respondent enterprise considers relevant to know the actual status of information integration among its partners.

2) In the automotive Brazilian sector exists cooperation mainly related to the first level supplier.

3) The information exchange with car makers is mainly demand, followed storage and production capacity. 
4) The respondent perception about information exchange importance is not confirmed when compared to the indexes that qualify the extent of information exchange between partners enterprises.

5) Analyzing the part 1questionnaire results with customer information exchange dendogram, Figure 2, the enterprise size has no significant influence on the SCCI pattern (see E4 and E8).

The present work is focused on customer and supplier integration. Future work would include the internal dimension of integration. It would be interesting to analyze the cooperation by information exchange considering all the elements of a supply chain from the final customer to the raw material suppliers. This study could identify local actions to be implemented to reach better performance for the entire supply chain. Also, would be interesting to calculate the information exchange assuming value between 0 to 1 to obtain to $\operatorname{IE}(\mathrm{s})$ and $\operatorname{IE}(\mathrm{c})$ in a continuous space between 0 and 1 , to consider different ways of information exchange on production, demand, capacity and storage. Finally this tool would be very useful in the establishment of investments in information technology.

\section{Acknowledgements}

The authors would like to thank the reviewers for their comments and suggestions for future work.

\section{References}

1. Barut, M., Faisst, W., Kanet, J.: Measuring Supply Chain Coupling: An Information System Perspective. European Journal of Purchasing \& Supply Management 8, 161-171 (2002)

2. Bowersox, D., Cross, D., Drayer, R.: The Digital Transformation - Technology and Beyond. Supply Chain Management Review, 22-29 (January/February 2005)

3. Fisher, L.M.: What is the right supply chain for your Product. Harvard Business Review, 105-116 (March/April 1997)

4. Flynn, B., Huo, B., Zhao, X.: The impact of supply chain integration on performance: A contingency and configuration approach. Journal of Operations Management 28, 58-71 (2010)

5. Frohlich, M.T., Westbrook, R.: Arcs of integration: an International Study of Supply Chain Strategies. Journal of Operation Management 19, 185-200 (2001)

6. Gustin, C.M., Daugherty, J.D.: The effects of Information availability on logistics integration. Journal of Business Logistics 16(1), 1-21 (1995) 